\title{
Impaired Error-Monitoring Function in People with Internet Addiction Disorder: An Event-Related fMRI Study
}

\author{
Guangheng Dong ${ }^{a}$ Yue Shen $^{b}$ Jie Huang ${ }^{a}$ Xiaoxia Duc \\ ${ }^{a}$ Department of Psychology, Zhejiang Normal University, Jinhua, ${ }^{b}$ Department of Psychology, \\ Liaoning Normal University, Dalian, and ' Department of Physics, Shanghai Key Laboratory of Magnetic Resonance, \\ East China Normal University, Shanghai, PR China
}

\section{Key Words}

Internet addiction · Error monitoring · Reward sensitivity

\begin{abstract}
Background: Internet addiction disorder (IAD) is rapidly becoming a prevalent mental health concern around the world. The neurobiological underpinnings of IAD should be studied to unravel the potential heterogeneity. This study was set to investigate the error-monitoring ability in IAD subjects. Methods: Fifteen IAD subjects and 15 healthy controls $(\mathrm{HC})$ participated in this study. Participants were asked to perform a fast Stroop task that may show error responses. Behavioral and neurobiological results in relation to error responses were compared between IAD subjects and $H C$. Results: Compared to HC, IAD subjects showed increased activation in the anterior cingulate cortex (ACC) and decreased activation in the orbitofrontal cortex following error responses. Significant correlation was found between ACC activation and the Internet addiction test scores. Conclusions: IAD subjects show an impaired error-monitoring ability compared to $\mathrm{HC}$, which can be detected by the hyperactivation in ACC in error responses.
\end{abstract}

Copyright ๑ 2013 S. Karger AG, Basel

\section{KARGER}

E-Mail karger@karger.com

www.karger.com/ear

\section{Introduction}

Internet addiction disorder (IAD), also described as pathological Internet use, is marked by an inability to control one's Internet use, which eventually leads to psychological, social or work difficulties [1-3]. Whether IAD is an addiction and whether it merits inclusion in DSM (Diagnostic and Statistical Manual of Mental Disorders)$\mathrm{V}$ is still in controversy [4]. In addition to this, the nosology and optimal diagnostic criteria for IAD remain controversial [4]. IAD is often considered a behavioral addiction and may share similar neuropsychological (i.e. development of euphoria, craving, and tolerance) and personality characteristics with other addictions [5], especially behavioral addiction [6]. Although significant prevalence estimates and associations with adverse consequences have been addressed [3,7-11], IAD has received relatively little study, particularly in its neurobiological underpinnings $[12,13]$.

What makes IAD subjects continue playing online even when faced to the severe negative consequences of their behaviors? One possible explanation, by analogizing with other addictions, is that their error-monitoring ability is impaired. Studies in gambling addiction, another type of 
behavioral addiction, showed that problem gambling was characterized by decreased sensitivity to loss and punishment [14-18]. Our previous functional magnetic resonance imaging (fMRI) study using a guessing task found that IAD subjects show decreased sensitivity to punishment [19]. Littel et al. [20] found impaired error-processing ability in excessive computer game players. In addition to this, impaired error processing was found in other types of addictions, such as cocaine dependence [21], nicotine dependence [22], cannabis users [23], and alcohol dependence [24]. As we mentioned above, IAD may share similar neuropsychological and personality characteristics with other addictions [5]. Thus, we speculate that the same condition might manifest in IAD subjects.

The role of the anterior cingulate cortex (ACC) in error processing was revealed by plenty of fMRI studies [25-27]. Researches in obsessive-compulsive disorder (OCD) $[28,29]$ and severe traumatic brain injury patients [30] showed hyperactivity in ACC in error responses, which suggested an impaired error-monitoring ability. IAD was speculated to be related to impaired inhibitory control or impulse control failure $[3,31]$. The preexisting impulsivity may increase one's vulnerability to develop addictive disorders and, conversely, engagement in addictive behaviors may exacerbate aspects of impulsivity [for review, see 32, 33]. IAD individuals demonstrate high impulsivity as measured by event-related potential (ERP) $[34,35]$ and self-report impulsivity results [36]. Thus, we may conclude that impaired error-monitoring ability might play an important role in the pathogenesis of IAD.

Error-monitoring ability is usually measured by errorrelated negativity (ERN) in ERP studies. When participants make errors in the fast response tasks, the ERN, presents as a negative deflection approximately 50-100 ms following the erroneous response $[37,38]$. The ERN reflects a response-conflict monitoring process and is thought to reflect error-processing activity of the ACC [39]. The literature is mixed in terms of whether higher error-monitoring performance is associated with enhanced or diminished regional blood oxygen level dependence (BOLD) signal, perhaps arising from methodological differences. First, studies in addiction subjects showed neural deficits associated with error processing $[18,23$, $24]$. Second, studies using fMRI also showed activity increases in this region on negative feedback $[40,41]$. Studies also proved that certain disturbances in cognition and behavior in common mental disorders such as schizophrenia and OCD can be understood as resulting from alternation in performance-monitoring functions associated with this region [42].
In view of the previous findings on error detection and the features of IAD, we hypothesized that IAD subjects show an impaired error-monitoring ability compared to healthy controls (HC), which can be detected by the changed activation in the ACC brain region in incorrect responses. To test this hypothesis, we used fMRI to compare the brain activities in a group of IAD subjects with that of a group of comparison subjects, using a fast colorword Stroop task that can produce response errors. We will test the following predictions: (1) the ACC will show increased/decreased activity in IAD subjects during incorrect response trials and (2) the degree of activation in incorrect response trials will show correlation with the severity of IAD symptoms.

\section{Methods}

\section{Participant Selection}

All participants were students recruited through advertisement in our university. They were all IAD participants suffering from the same Internet behavior, namely online gaming. IAD was determined based on Young's online Internet addiction test (IAT) (http://www.netaddiction.com) scores of 80 or higher (mean = $84.4, \mathrm{SD}=4.36$ ). The IAT has been proven a valid and reliable instrument for classifying IAD [43, 44]. The IAT consists of 20 items associated with online Internet use, including psychological dependence, compulsive use, withdrawal, related problems in school or work, sleep, family or time management. For each item, a graded response is selected from $1=$ 'rarely' to $5=$ 'always' or 'does not apply'. Scores over 50 indicate occasional or frequent Internet-related problems and scores over 80 indicate significant IAD-related life problems (http://www.netaddiction.com). In the present study, HC scored lower than 30 on Young's IAT (mean $=14.3, \mathrm{SD}$ $=2.17$ ). In addition to this, all participants meeting criteria for IAD fulfilled the subgroup classification of Internet gaming addiction by reporting spending most of their time online $(>80 \%)$ playing games.

Sixteen IAD subjects and $16 \mathrm{HC}$ were recruited in this study. Two of them were excluded from further analysis because of their responses [their accuracy rates are too low $(<80 \%)$ or too high $(100 \%)]$. The remaining 30 participants were right handed, nonsmoking males (15 IAD and $15 \mathrm{HC}$ ). The IAD and HC groups did not significantly differ in age (mean IAD $=23.8$ years, $\mathrm{SD}=3.7$; mean $\mathrm{HC}=24.1$ years, $\mathrm{SD}=3.3$ ). Only males were included due to a higher IAD prevalence in men than women. Participants were recruited through advertisements and all were free of active substance abuse, axis I psychiatric disorders, neurological, or medical disorders. They underwent structured psychiatric interviews (MINI) performed by an experienced psychiatrist with an administration time of approximately $15 \mathrm{~min}$. The MINI was designed to meet the need for a short but accurate structured psychiatric interview for multicenter clinical trials and epidemiology studies [45]. All participants were free of axis I psychiatric disorders listed in the MINI. IAD and HC reported alcohol use, but did not fulfill the DSM-IV abuse or dependence criteria. They were medication free and were instructed not to use any substances of 
abuse, including coffee, on the day of scanning. The Human Investigations Committee of Zhejiang Normal University (2011.2) approved this research. All participants provided written informed consent.

\section{Task and Procedure}

An event-related color-word fMRI Stroop task was used in our study. Three target color words (e.g. red, green, yellow) were presented randomly in congruent (e.g. the word 'RED' in red ink) or incongruent (e.g. the word 'RED' in green ink) trials. The task consisted of 2 sessions of 123 trials each. Each trial was presented for 2,000 ms, and participants were asked to press a button to indicate the ink color of the word as soon as possible using 3 buttons (i.e. green $=$ thumb, red $=$ index finger, yellow $=$ middle finger) of a 5-button response box (Invivo Corp., http://www.invivocorp.com/). A black screen appeared for a random interval of 600-1,400 ms (average 1,000 ms) between the trials. Stimuli were presented and behavioral data were collected using E-prime software (Psychology Software Tools, Inc.). Each condition (incongruent, congruent) accounted for $50 \%$ and all trials were presented randomly.

Participants were guaranteed USD 50 for participation, and to encourage a quick and accurate task performance, they were told that they would be rewarded with an additional USD 0-50 based on their task performance $[1 /($ reaction time $\times$ error rate $)]$. Participants completed an out-of-scanner practice session which continued until they reached an accuracy rate of $90 \%$ or higher.

\section{Image Acquisition and Preprocessing}

fMRI was performed on a $3 \mathrm{~T}$ system (Siemens Trio) with a gradient-echo EPI T2-sensitive pulse sequence in 33 slices (interleaved sequence, $3 \mathrm{~mm}$ thickness, $\mathrm{TR}=2,000 \mathrm{~ms}$, $\mathrm{TE}=30$, flip angle $90^{\circ}$, field of view $220 \times 220 \mathrm{~mm}^{2}$, matrix $64 \times 64$ ). Stimuli were presented using the Invivo synchronous system (Invivo Company, http://www.invivocorp.com/) through a monitor in the head coil, enabling participants to view the stimuli presented on the screen.

Imaging analysis was conducted using SPM8 (http://www.fil. ion.ucl.ac.uk/spm). Images were slice-timed, reoriented, and realigned to the first volume. T1-co-registered volumes were then normalized to an SPM T1 template resulting in an isometric voxel size of $3 \times 3 \times 3 \mathrm{~mm}^{3}$ and spatially smoothed using an 8 - $\mathrm{mm}$ fullwidth-at-half-maximum Gaussian kernel.

\section{First-Level fMRI Analysis}

A general linear model (GLM) was applied to identify the blood oxygen level dependence (BOLD) signal in relation to two event types of interest: error and right response trials. The numbers of error responses in the participants ranged from 3-20 (mean 8.4). Since there were error responses not only in incongruent trials, but also in congruent trials, we did not exclude the right responses trials in congruent condition (for detailed behavioral data see the 'Behavioral Performance' chapter). Six head movement predictors derived from the realignment stage were included in the GLM design matrix as covariates of no interest. The GLM was independently applied to each voxel to identify voxels that were significantly activated for the event types of interest. A high-pass filter (cutoff period = $128 \mathrm{~s}$ ) was applied to improve the signal-to-noise ratio by filtering out low-frequency noise.

Error Monitoring in Internet Addicts

\section{Second Level Group fMRI Analysis}

Second level analyses, performed at the group level, treated intersubject variability as a random effect. Firstly, we determined which voxels showed a main effect of incorrect response versus correct response trials within each group (IAD and HC). Secondly, we tested which voxels significantly differed in BOLD signal between the IAD and $\mathrm{HC}$ groups $\left[\left(\mathrm{IAD}_{\text {incorrect }}-\mathrm{IAD}_{\text {correct }}\right)-\left(\mathrm{HC}_{\text {incorrect }}{ }^{-}\right.\right.$ $\left.\mathrm{HC}_{\text {correct }}\right)$ ], after correcting for multiple testing at the whole brain level with false discovery rate (FDR) to a threshold of $\mathrm{p}<0.05$. Finally, we extracted the BOLD signal from the peak voxel within each cluster that demonstrated between-group differences and entered these data for all participants into correlation analyses with correct incongruent trial reaction time, accuracy rate and Young's IAT score.

\section{Correlation Analysis}

Correlation analysis was performed between brain activities and the behavioral performances to support our hypothesis. We calculated two correlations. First, correlation between the brain activity (beta value) in ACC and the IAT score in the IAD group. Second, we calculated the correlation between the peak activity (beta value) in ACC and the accuracy rate during this task.

\section{Results}

\section{Behavioral Performances}

Behavioral performances were calculated between different groups using the nonparametric independent $t$ test. IAD subjects showed lower accuracy rates and longer response times. However, no significant difference was found in accuracy rates and reaction times between the IAD and $\mathrm{HC}$ groups (table 1).

\section{Imaging Results}

A group (IAD, HC) condition (correct, incorrect) ANOVA revealed that IAD subjects displayed a higher activation in ACC (Brodmann's area 24) and a decreased activation in the orbitofrontal cortex (OFC) (Brodmann's area 11) in frontal brain areas when compared to $\mathrm{HC}$ (fig. 1, table 2). The beta figure of ACC shows that this difference was caused mostly by the enhanced brain activity in incorrect responses and the decreased brain activity in correct responses in IAD subjects.

\section{Correlation Analysis}

We analyzed the correlation between error-related ACC activity (beta value) and the IAT scores and accuracy rate. Marginally significant correlation was found between ACC activity and the IAT score ( $\mathrm{r}=0.381, \mathrm{p}=$ 0.056). No significant correlation was found between ACC activation and accuracy rates in all subjects $(r=$ $0.101, \mathrm{p}=0.263$; fig. 2). 


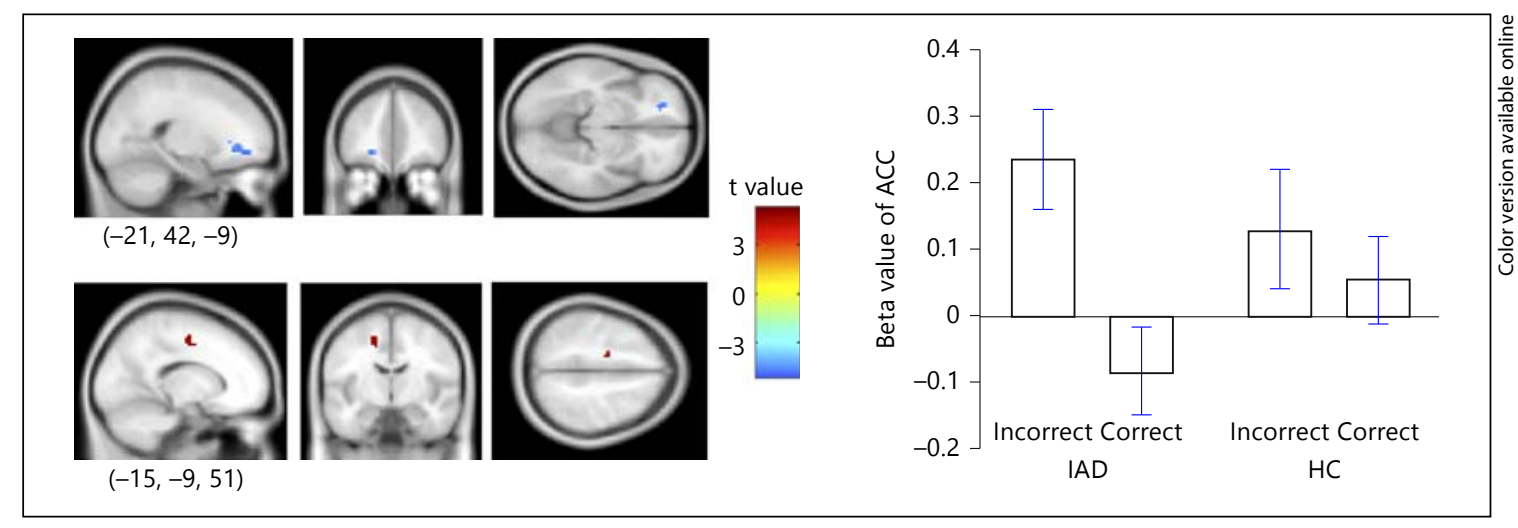

Fig. 1. Left panel: activation differences in IAD subjects and $\mathrm{HC}$ following incorrect responses $(\mathrm{p}<0.05, \mathrm{FDR}$ corrected and with extent threshold: $k>10$ voxels; voxel size $=3 \times 3 \times 3$ ). The figures are shown in different coordinates to give the best view of the results. Right panel: beta figure of ACC in correct and incorrect responses.

Table 1. Behavioral results of the Stroop task in different groups (mean \pm SD)

\begin{tabular}{lcccc}
\hline & Internet addicts & HC & t value & Sig (2-tailed) \\
\hline Accuracy rate & & & & \\
$\quad$ Congruent trials & $0.959 \pm 0.056$ & $0.978 \pm 0.013$ & -1.267 & 0.224 \\
$\quad$ Incongruent trials & $0.939 \pm 0.051$ & $0.947 \pm 0.046$ & -0.436 & 0.667 \\
$\quad$ All trials & $0.956 \pm 0.032$ & $0.962 \pm 0.027$ & -0.592 & 0.558 \\
Reaction time, ms & & & & \\
$\quad$ Congruent trials & $686 \pm 140$ & $595 \pm 90$ & 2.104 & 0.046 \\
Incongruent trials & $786 \pm 165$ & $699 \pm 137$ & 1.577 & 0.126 \\
$\quad$ Right responses & $733 \pm 148$ & $643 \pm 110$ & 1.892 & 0.070 \\
$\quad$ Error responses & $778 \pm 208$ & $765 \pm 213$ & 0.164 & 0.871 \\
$\quad$ All trials & $736 \pm 151$ & $657 \pm 114$ & 1.609 & 0.120 \\
\hline
\end{tabular}

\section{Discussion}

This study investigated the error-monitoring ability in IAD subjects compared to $\mathrm{HC}$ with a Stroop task. The results of this study support to the hypothesis that ACC hyperactivity in IAD plays an important role in the pathogenesis of this disorder.

\section{Hyperactivation in ACC and Impaired Error- Monitoring Ability}

Consistent with our hypothesis, IAD subjects showed a more enhanced ACC activation than $\mathrm{HC}$ after incorrect responses. This result is in agreement with the errormonitoring features found in $\operatorname{OCD}[28,29]$ and severe traumatic brain injury [30] patients that were supposed to have a more impaired error-monitoring ability than HC. However, it contradicts the results from several ERP $[20,22]$ and fMRI $[23,24]$ studies that found lower activations in addiction groups.
The discrepancy between the present and previous results might have several reasons. First, it might be caused by different tasks used in the studies. For example, Luijten et al. [22] employed a flanker task and Hester et al. [23] a go/no-go task, and Li et al. [24] used a stop signal task in their studies. Different tasks might bring different features of the error responses. Second, the difference might be caused by the characteristics of the Stroop task employed in this study. Most Stroop tasks focus on either reaction speed or accuracy during responses. However, in our study, we asked them to respond 'quickly and accurate'.

Besides to the imaging results, the outcomes also show that ACC activation is positively related with IAT scores, which means that people who have a higher IAT score show a higher ACC activation. The beta figure of ACC shows that this difference is caused by the enhanced brain activity in incorrect responses and decreased brain activity in correct responses in IAD subjects. This suggests that IAD subjects reacted much fiercer than $\mathrm{HC}$ to their selec- 


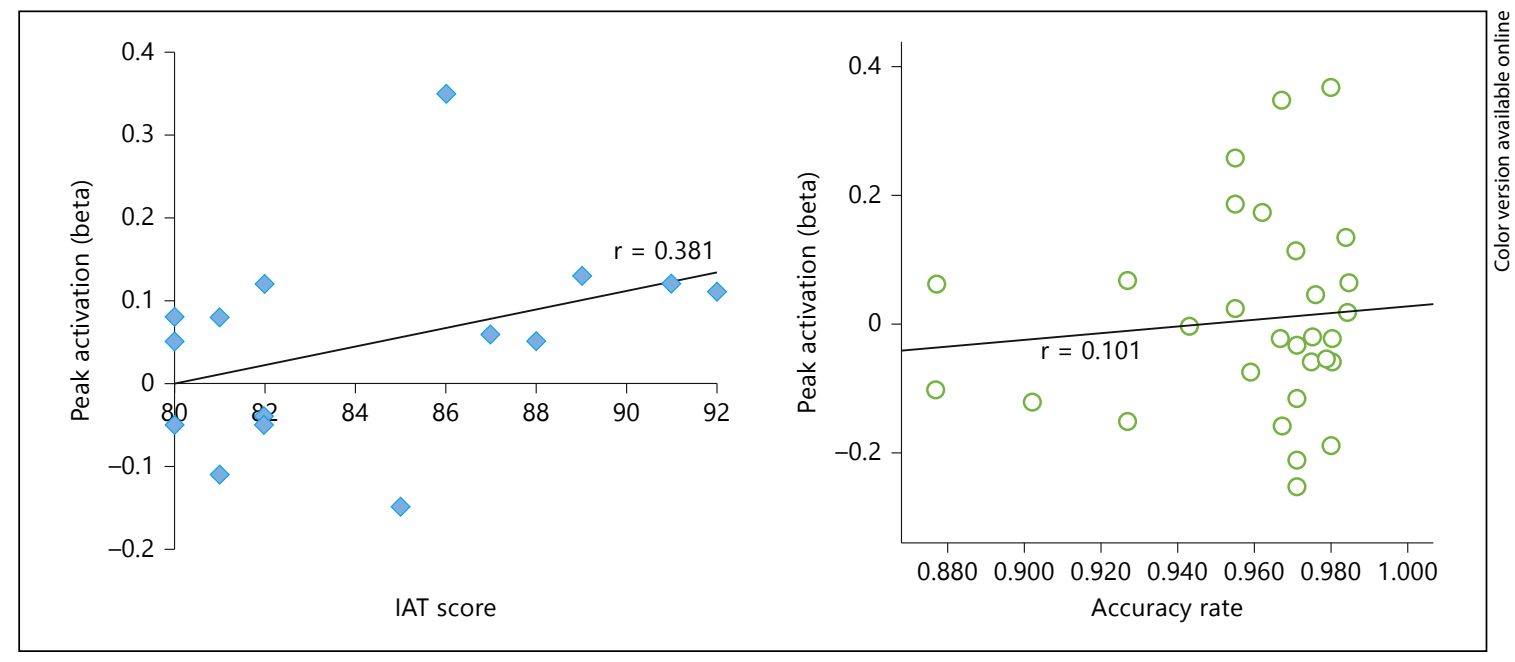

Fig. 2. Correlation between ACC activation and IAT score in IAD subjects (left panel). Correlation between ACC activation and accuracy rate in all subjects (right panel).

Table 2. Regional brain activity changes in Internet addicts and HC

\begin{tabular}{lllllc}
\hline $\mathrm{x} / \mathrm{y} / \mathrm{z}^{\mathrm{a}}$ & $\begin{array}{l}\text { Peak } \\
\text { t value }\end{array}$ & $\begin{array}{l}\text { Number } \\
\text { of voxels }\end{array}$ & $\begin{array}{l}\text { FDR corrected } \\
\mathrm{p} \text { value }\end{array}$ & Brain region $^{\mathrm{c}}$ & \begin{tabular}{l} 
Brodmann's $_{\text {area }}$ \\
\hline $\begin{array}{c}\text { Increased } \\
-15 /-9 / 52\end{array}$
\end{tabular} \\
$\begin{array}{c}\text { Decreased } \\
-21 / 42 /-9\end{array}$ & -4.3006 & 13 & 0.031 & Left ACC & 24 \\
\hline
\end{tabular}

${ }^{a}$ Peak MNI coordinates. ${ }^{\mathrm{b}} \mathrm{p}<0.05$, FDR corrected and at least 10 voxels; voxel size $=3 \times 3 \times 3 .{ }^{\mathrm{c}}$ The brain regions were referenced to the software Xjview (http://www.alivelearn.net/xjview8) and double-checked with an atlas.

tion results. From the results we discussed, we may speculate that hyperactivation in ACC in incorrect trials means that the error-monitoring ability was impaired in IAD subjects.

There are three theories explaining why a higher ACC activation indicates an impaired error-monitoring ability in IAD subjects. First, higher activation in incorrect responses reflected subjects' experience to correct their actions repeatedly [46]. Previous studies showed that following conflict detection, regions associated with attentional control were engaged to resolve the conflict [42], and the increased activity in ACC reflected the detection that an error was made based on a comparison between actual movement and the intended movement [47, 48]. From this point of view, IAD subjects need more attentional endeavor to check their error behaviors (conflicts) and correct their actions during the error-monitoring process compared to HC. Second, in ERP studies, re- searchers believe that higher error-related activation means that subjects cannot disengage from the processing of distressing thoughts, and therefore have an increased ERN [49-51]. The higher activation seen in the fMRI results may also reflect this mental process. Based on this theory, IAD subjects are supposed to recover much harder from the distressing thoughts caused by their error responses. Third, the disruption of ACC functioning contributes to impaired cognitive control in IAD through impairment in its performance-monitoring function [52]. In the presence of response conflict, people are known to sometimes make impulsive errors based on partial, incomplete analysis of the stimulus. Executive control ability is responsible for all these controlling and regulating actions. Error-monitoring ability is one of the subtype functions of executive control ability. Previous studies have proven that IAD subjects show impaired executive control ability compared to HC $[53,54]$. Thus, an 
impaired executive control ability may contribute to an impaired error-monitoring ability in IAD subjects. All these theories sound reasonable and may provide some explanations for the higher activation in ACC and impaired error-monitoring ability in IAD subjects.

\section{Decreased OFC Activation and Sensitivity to \\ Punishment}

It is widely agreed that the OFC is important for valueguided behaviors $[55,56]$. Neuroimaging studies found that OFC was activated by pleasant touch and rewarding $[57,58]$. A hallmark personality characteristic in IAD is impulsivity, which is often characterized by enhanced sensitivity to reward and reduced sensitivity to punishment $[10,19]$. This is similar to other types of addictions [59-61]. The decreased activation of the OFC might be explained by a lower sensitivity to reward or punishment. In this study, we focused on subjects' error-monitoring ability; however, a quick and accurate task performance was incentivized by informing the participants that they would be rewarded with additional payments based on their performance, which may have led to recruitment of reward-related circuitry during task performance. More error responses denote less additional reward for the participant. The reward sensitivity to the incentives may lead to OFC activation differences in the different groups.
This means that IAD subjects show less sensitivity to the potential loss concerning their behaviors. In summary, the decreased sensitivity to punishment may provide some explanation why IAD subjects show decreased OFC activation compared to HC in this study.

The results from this study revealed several important findings that can deepen our understanding about the biological reactions of Internet addiction. However, several limitations should be considered. First, the present study only revealed the current mental states of the IAD subjects, we cannot conclude whether they are reasons of IAD or results from IAD. Future studies should pay attention to this issue. Second, the behavioral results do not provide strong support to the imaging results, which limits the whole discussion on why there was a higher ACC activation.

\section{Acknowledgements}

This research was supported by the National Science Foundation of China (30900405).

\section{Disclosure Statement}

The authors have no conflicts of interest to disclose.

\section{References}

1 Davis RA: Cognitive-behavioral model of pathological Internet use. Comput Human Behav 2001;17:187-195.

-2 Young KS, Rogers RC: The relationship between depression and Internet addiction. $\mathrm{Cy}-$ berpsychol Behav 1998;1:25-28.

3 Young KS: Internet addiction: the emergence of a new clinical disorder. Cyberpsychol Behav 1998;1:237-244.

$\checkmark 4$ Block JJ: Issues for DSM-V: Internet addiction. Am J Psychiatry 2008;165:306-307.

-5 Grant JE, Potenza MN, Weinstein A, Gorelick DA: Introduction to behavioral addictions. Am J Drug Alcohol Abuse 2010;36:233-241.

-6 Potenza MN, Leung HC, Blumberg HP, Peterson BS, Fulbright RK, Lacadie CM, Skudlarski P, Gore JC: An fMRI Stroop task study of ventromedial prefrontal cortical function in pathological gamblers. Am J Psychiatry 2003;160:1990-1994.

7 Kim JH, Lau CH, Cheuk KK, Kan P, Hui HL, Griffiths SM: Predictors of heavy Internet use and associations with health-promoting and health risk behaviors among Hong Kong niversity students. J Adolesc 2010;33:215-220.
8 Niemz K, Griffiths M, Banyard P: Prevalence of pathological Internet use among university students and correlations with self-esteem, the General Health Questionnaire (GHQ), and disinhibition. Cyberpsychol Behav 2005; 8:562-570.

-9 Dong G, Lu Q, Zhou H, Zhao X: Precursor or sequela: pathological disorders in people with Internet addiction disorder. PLoS ONE 2011; 6:e14703.

10 Dong G, Devito E, Huang J, Du X: Diffusion tensor imaging reveals thalamus and posterior cingulate cortex abnormalities in Internet gaming addicts. J Psychiatr Res 2012;46: 1212-1216.

11 Dong G, Huang J, Du X: Alterations in regional homogeneity of resting-state brain activity in Internet gaming addicts. Behav Brain Funct 2012;8:41.

$\$ 12$ Block JJ: Prevalence underestimated in problematic Internet use study. CNS Spectr 2006; 12:14-15.

13 Liu T, Potenza MN: Problematic Internet use: clinical implications. CNS Spectr 2007;12: 453-466.
14 van Holst RJ, van den Brink W, Veltman DJ, Goudriaan AE: Why gamblers fail to win: a review of cognitive and neuroimaging findings in pathological gambling. Neurosci Biobehav Rev 2010;34:87-107.

15 Goudriaan AE, Oosterlaan J, De Beurs E, Van Den Brink W: Decision making in pathological gambling: a comparison between pathological gamblers, alcohol dependents, persons with Tourette syndrome, and normal controls. Cogn Brain Res 2005;23:137-151.

-16 Cavedini P, Riboldi G, Keller R, D’Annucci A, Bellodi L: Frontal lobe dysfunction in pathological gambling patients. Biol Psychiatry 2002;51:334-341.

17 Petry NM: Pathological gamblers, with and without substance use disorders, discount delayed rewards at high rates. J Abnorm Psychol 2001;110:482-487.

18 de Ruiter MB, Oosterlaan J, Veltman DJ, van den Brink W, Goudriaan AE: Similar hyporesponsiveness of the dorsomedial prefrontal cortex in problem gamblers and heavy smokers during an inhibitory control task. Drug Alcohol Depend 2012;121:81-89. 
19 Dong G, Huang J, Du X: Enhanced reward sensitivity and decreased loss sensitivity in Internet addicts: an fMRI study during a guessing task. J Psychiatric Res 2011;45:1525-1529.

20 Littel M, van den Berg I, Luijten M, van Rooij AJ, Keemink L, Franken IH: Error processing and response inhibition in excessive computer game players: an event-related potential study. Addict Biol 2012;17:934-947.

21 Franken IH, van Strien JW, Franzek EJ, van de 36 Wetering BJ: Error-processing deficits in patients with cocaine dependence. Biol Psychol 2007;75:45-51.

22 Luijten M, van Meel CS, Franken IH: Diminished error processing in smokers during smoking cue exposure. Pharmacol Biochem Behav 2011;97:514-520.

-23 Hester R, Nestor L, Garavan H: Impaired error awareness and anterior cingulate cortex hypoactivity in chronic cannabis users. Neuropsychopharmacology 2009;34:2450-2458.

24 Li CS, Luo X, Yan P, Bergquist K, Sinha R: Altered impulse control in alcohol dependence: neural measures of stop signal performance. Alcohol Clin Exp Res 2009;33:740-750.

-25 Hester R, Fassbender C, Garavan H: Individual differences in error processing: a review and reanalysis of three event-related fMRI studies using the GO/NOGO task. Cereb Cortex 2004;14:986-994.

-26 Menon V, Adleman NE, White CD, Glover $\mathrm{GH}$, Reiss AL: Error-related brain activation during a Go/NoGo response inhibition task. Hum Brain Mapp 2001;12:131-143.

-27 Ridderinkhof KR, Ullsperger M, Crone EA, Nieuwenhuis S: The role of the medial frontal cortex in cognitive control. Science 2004;306: 443-447.

-28 Fitzgerald KD, Welsh RC, Gehring WJ, Abelson JL, Himle JA, Liberzon I, Taylor SF: Error-related hyperactivity of the anterior cingulate cortex in obsessive-compulsive disorder. Biol Psychiatry 2005;57:287-294.

29 Hajcak G, Franklin ME, Foa EB, Simons RF: Increased error-related brain activity in pediatric obsessive-compulsive disorder before and after treatment. Am J Psychiatry 2008; 165:116-123.

30 Sozda CN, Larson MJ, Kaufman DA, Schmalfuss IM, Perlstein WM: Error-related processing following severe traumatic brain injury: an event-related functional magnetic resonance imaging (fMRI) study. Int J Psychophysiol 2011;82:97-106.

- 31 Dong G, Devito EE, Du X, Cui Z: Impaired inhibitory control in 'Internet addiction disorder': a functional magnetic resonance imaging study. Psychiatry Res 2012;203:153158.

32 de Wit H: Impulsivity as a determinant and consequence of drug use: a review of underlying processes. Addict Biol 2009;14:22-31.

-33 Dick DM, Smith G, Olausson P, Mitchell SH, Leeman RF, O'Malley SS, Sher K: Understanding the construct of impulsivity and its relationship to alcohol use disorders. Addict Biol 2010;15:217-226.
34 Dong G, Zhou H, Zhao X: Impulse inhibition in people with Internet addiction disorder: electrophysiological evidence from a Go/ NoGo study. Neurosci Lett 2010;485:138142.

35 Dong G, Zhou H, Zhao X: Male Internet addicts show impaired executive control ability: evidence from a color-word Stroop task. Neurosci Lett 2011;499:114-118.

6 Cao F, Su L, Liu T, Gao X: The relationship between impulsivity and Internet addiction in a sample of Chinese adolescents. Eur Psychiatry 2007;22:466-471.

37 Falkenstein M, Hohnsbein J, Hoormann J, Blanke L: Effects of crossmodal divided attention on late ERP components. II. Error processing in choice reaction tasks. Electroencephalogr Clin Neurophysiol 1991;78:447455.

38 Falkenstein M, Hoormann J, Hohnsbein J: Changes of error-related ERPs with age. Exp Brain Res 2001;138:258-262.

39 Olvet DM, Hajcak G: The error-related negativity (ERN) and psychopathology: toward an endophenotype. Clin Psychol Rev 2008;28: 1343-1354.

40 Knutson JS, Kilgore KL, Mansour JM, Crago PE: Intrinsic and extrinsic contributions to the passive moment at the metacarpophalangeal joint. J Biomech 2000;33:1675-1681.

41 Ullsperger M, von Cramon DY: Error monitoring using external feedback: specific roles of the habenular complex, the reward system, and the cingulate motor area revealed by functional magnetic resonance imaging. Neurosci 2003;23:4308-4314.

42 Van Veen V, Carter CS: The timing of actionmonitoring processes in the anterior cingulate cortex. J Cogn Neurosci 2002;14:593602.

43 Widyanto L, McMurran M: The psychometric properties of the Internet addiction test. Cyberpsychol Behav 2004;7:443-450.

44 Widyanto L, Griffiths MD, Brunsden V: A psychometric comparison of the Internet Addiction Test, the Internet-Related Problem Scale, and self-diagnosis. Cyberpsychol Behav Soc Netw 2011;14:141-149.

45 Lecrubier Y, Sheehan DV, Weiller E, Amorim P, Bonora I, Harnett Sheehan K, Janavs J, Dunbar GC: The MINI International Neuropsychiatric Interview (M.I.N.I.). A short diagnostic structured interview: reliability and validity according to the CIDI. Eur Psychiatry 1997;12:224-231.

46 Pitman RK, Orr SP, Forgue DF, de Jong JB, Claiborn JM: Psychophysiologic assessment of posttraumatic stress disorder imagery in Vietnam combat veterans. Arch Gen Psychiatry 1987;44:970-975
47 Carter CS, Braver TS, Barch DM, Botvinick MM, Noll D, Cohen JD: Anterior cingulate cortex, error detection, and the online monitoring of performance. Science 1998;280: 747-749.

48 Kiehl KA, Liddle PF, Hopfinger JB: Error processing and the rostral anterior cingulate: an event-related fMRI study. Psychophysiology 2000;37:216-223.

49 Luu CD, Green JF, Abel L: Vertical fixation disparity curve and the effects of vergence training in a normal young adult population. Optom Vis Sci 2000;77:663-669.

50 Gehring WJ, Knight RT: Prefrontal-cingulate interactions in action monitoring. Nat Neurosci 2000;3:516-520.

51 Gehring WJ, Willoughby AR: The medial frontal cortex and the rapid processing of monetary gains and losses. Science 2002;295: 2279-2282.

-52 Garavan H, Kaufman JN, Hester R: Acute effects of cocaine on the neurobiology of cognitive control. Philos Trans R Soc Lond B Biol Sci 2008;363:3267-3276.

53 Coffey SF, Gudleski GD, Saladin ME, Brady KT: Impulsivity and rapid discounting of delayed hypothetical rewards in cocaine-dependent individuals. Exp Clin Psychopharmacol 2003;11:18-25.

54 Monterosso JR, Aron AR, Cordova X, Xu J, London ED: Deficits in response inhibition associated with chronic methamphetamine abuse. Drug Alcohol Depend 2005;79:273277.

55 Rangel A, Camerer C, Montague PR: A framework for studying the neurobiology of valuebased decision making. Nat Rev Neurosci 2008;9:545-556.

56 Rushworth MF, Behrens TE, Rudebeck PH, Walton ME: Contrasting roles for cingulate and orbitofrontal cortex in decisions and social behaviour. Trends Cogn Sci 2007;11:168176

57 Rolls ET, Larry RS: Reward neurophysiology and orbitofrontal cortex; in Encyclopedia of Neuroscience. Oxford, Academic Press, 2009, pp 319-324.

-58 Gallagher M, McMahan RW, Schoenbaum G: Orbitofrontal cortex and representation of incentive value in associative learning. J Neurosci 1999;19:6610-6614.

59 Finn PR, Hall J: Cognitive ability and risk for alcoholism: short-term memory capacity and intelligence moderate personality risk for alcohol problems. J Abnorm Psychol 2004;113: 569-581.

60 Grant JD, Scherrer JF, Lyons MJ, Tsuang M, True WR, Bucholz KK: Subjective reactions to cocaine and marijuana are associated with abuse and dependence. Addict Behav 2005; 30:1574-1586.

61 Petry NM, Bickel WK, Arnett M: Shortened time horizons and insensitivity to future consequences in heroin addicts. Addiction 1998; 93:729-738. 